\title{
Review
}

\section{Functional Differences Between Direct and Indirect Striatal Output Pathways in Huntington's Disease}

\author{
Laurie Galvan, Véronique M. André, Elizabeth A. Wang, Carlos Cepeda and Michael S. Levine* \\ Intellectual and Developmental Disabilities Research Center, Semel Institute for Neuroscience and Human Behavior \\ and the Brain Research Institute, David Geffen School of Medicine, University of California Los Angeles, \\ Los Angeles, CA, USA
}

\begin{abstract}
There is morphological evidence for differential alterations in striatal medium-sized spiny neurons (MSNs) giving rise to the direct and indirect output pathways in Huntington's disease (HD). MSNs of the indirect pathway appear to be particularly vulnerable and markers for these neurons are lost early in postmortem brains and in genetic mouse models. In contrast, MSNs of the direct pathway appear to be relatively spared in the early stages. Because of the great morphological and electrophysiological similarities between MSNs of these pathways, until recently it was difficult to tease apart their functional alterations in HD models. The recent use of the enhanced green fluorescent protein gene as a reporter to identify dopamine D1 (direct pathway) and D2 (indirect pathway) receptor-expressing MSNs has made it possible to examine synaptic function in each pathway. The outcomes of such studies demonstrate significant time-dependent changes in the balance of excitatory and inhibitory inputs to both direct and indirect pathway MSNs in HD and emphasize early increases in both excitatory and inhibitory inputs to direct pathway MSNs. There also is a strong influence of alterations in dopamine modulation that possibly cause some of the changes in excitatory and inhibitory synaptic transmission in the HD models. These changes will markedly alter the output structures, the GPi and the SNr. In the future, the use of combined optogenetics with identified neurons in each pathway will help unravel the next set of questions about how the output nuclei are affected in HD.
\end{abstract}

Keywords: Medium-sized spiny neurons, excitation, inhibition, Huntington's disease, dopamine modulation

\section{INTRODUCTION}

Huntington's disease (HD), an inherited, autosomal dominant neurodegenerative disorder, is due to a mutation in the IT15 gene located on chromosome 4 [1]. It is a progressive disease characterized by motor symptoms manifesting as chorea in early stages and as akinesia and dystonia in later stages.

*Correspondence to: Michael S. Levine, PhD, IDDRC Room 58258, Semel Institute for Neuroscience and Human Behavior, UCLA School of Medicine, 760 Westwood Plaza, Los Angeles, CA 90095 , USA. Tel.: +1 310825 7595; Fax: +1 310206 5060; E-mail: mlevine@mednet.ucla.edu.
Symptoms also include psychiatric and cognitive disturbances [2, 3]. In HD, the greatest neuropathology is observed in the striatum and the cortex although other nuclei including the globus pallidus (GP), thalamus, hypothalamus, subthalamic nucleus, substantia nigra (SN) and cerebellum are affected, especially in later stages [4-7]. In the striatum, there is massive loss of medium-sized spiny neurons (MSNs) [8]. However, not all MSNs appear equally vulnerable as neuronal loss proceeds from dorsal to ventral regions [9]. Striatal interneurons are relatively spared in HD $[9,10]$ and apparent losses can be explained by reduced protein expression [11]. In the cerebral cortex 
there is both laminar thinning and white matter loss [12].

\section{STRIATAL INPUTS AND OUTPUTS}

MSNs constitute $90-95 \%$ of all striatal neurons and utilize GABA as their principal neurotransmitter [13] as well as colocalizing specific neuropeptides. The striatum receives glutamatergic inputs from almost all neocortical areas [14] and specific thalamic nuclei $[15,16]$. These inputs primarily synapse onto spines of MSNs [17]. The striatum also contains a number of modulatory components including dopamine (DA) from projections in the SN pars compacta $(\mathrm{SNc})$ [18] and cholinergic or GABAergic inputs from striatal interneurons [19, 20]. The large aspiny cholinergic interneurons and the numerous other interneuronal GABAergic populations are relatively spared from degeneration in HD [8, 21-23].

Striatal output is primarily divided into two populations of MSNs (the direct and indirect pathways) with distinct projections, as well as DA receptor and neuropeptide expression [24], although some overlap exists [24-27]. The direct pathway consists of MSNs that predominantly express D1 DA receptors [28] as well as substance P (SP) [29] and dynorphin [30] and project to the $\mathrm{SN}$ pars reticulata $(\mathrm{SNr})$ and the internal segment of the GP (GPi) [28, 31]. The indirect pathway consists of MSNs that express predominantly D2 receptors [28], met-enkephalin or neurotensin [29, 32] and project to the external segment of the GP (GPe) [24].

The differences between the two output pathways are important in HD as there is morphological evidence during disease progression for time-dependent, differential alterations in the two populations of striatal projection neurons. MSNs of the indirect pathway appear to be particularly vulnerable in HD and markers for these neurons and their projections, such as enkephalin, are lost in postmortem brains of fully symptomatic patients, in early symptomatic and presymptomatic brains and in genetic mouse models [33-37]. In contrast, MSNs of the direct pathway are relatively spared in the early stages, although the SP-containing projections to the $\mathrm{SNr}$ are more severely affected than the SP-containing projections to the GPi and SNc [38]. These results are consistent with the hypothesis that chorea results from preferential dysfunction with ultimate loss of indirect pathway MSNs and that akinesia and dystonia, which occur later in $\mathrm{HD}$, are a consequence of the addi- tional dysfunction and loss of direct pathway MSNs [39]. However, it is unclear whether the early loss of enkephalin immunoreactivity in the GPe reflects a depletion of peptide content or a degenerative loss of indirect pathway MSNs and axonal inputs to the GPe. If the neurons of the indirect pathway become dysfunctional and/or degenerate, a change or loss of input to the GPe will induce an imbalance in the basal ganglia output circuit. In addition, there is some evidence for early alterations in MSNs originating the direct pathway, which also could lead to disinhibition of thalamocortical pathways [40, 41].

One of the important challenges and enigmas for understanding HD pathology is defining the unique underlying mechanisms of striatal MSN susceptibility and the potential differential susceptibility of the direct and indirect striatal output pathways. What makes MSNs more susceptible to degeneration and why are indirect pathway MSNs potentially susceptible earlier than direct pathway MSNs? Although there has been much work examining MSN susceptibility in HD (see [42] for a comprehensive review) and one of the most recently generated hypotheses has pointed to excitotoxic effects of aberrant N-methyl-D-aspartate (NMDA) receptor synaptic and extrasynaptic signaling $[43,44]$, there are no studies systematically examining functional alterations of the MSNs of the direct and indirect output pathways. Previously, it was extremely difficult to isolate direct and indirect pathway MSNs for such analyses. Recently, the use of the enhanced green fluorescent protein (EGFP) gene as a reporter to identify DA D1 (direct pathway) and D2 (indirect pathway) receptor-expressing striatal cells has made it possible to identify and separately study neurons originating each pathway. The purpose of this review will be to summarize our knowledge of the functional role of these two pathways and the changes that occur in each during progression of the HD phenotype in mouse models.

\section{DIFFERENTIAL PROPERTIES OF DIRECT AND INDIRECT OUTPUT PATHWAY MSNS}

In intact mice, anatomical evidence has demonstrated differential cortical excitatory inputs onto direct and indirect pathway MSNs. Two types of pyramidal corticostriatal projections have been identified; one is ipsilateral and arises from collaterals of the pyramidal tract (PT-type), and the other is bilateral and projects only intratelencephalically to the cortex and striatum (IT-type). The corticostriatal terminals 
from IT-type neurons are smaller than those from PT-type neurons [45]. Terminals making asymmetric axospinous contacts with direct pathway MSNs are significantly smaller than those contacting indirect pathway MSNs [46], suggesting that direct pathway neurons preferentially receive inputs from IT-type cortical neurons, whereas indirect pathway neurons receive greater inputs from PT-type cortical neurons. A possible functional consequence of this differential innervation is that indirect pathway cells would be subject to increased glutamate release from corticostriatal terminals [45] (however see [47]), which could make them more susceptible to excitotoxic influences in HD as the major glutamate input comes from the cortex.

Although it was generally believed that MSNs of the direct and indirect pathways were morphologically and electrophysiologically identical, this assumption has changed [25, 48-50]. While most studies using in vitro preparations have shown few differences in basic membrane properties in direct and indirect pathway MSNs [48, 50], there is evidence that indirect pathway MSNs may be more excitable [48-50] and could be more susceptible to abnormal glutamate release or receptor dysfunction as might occur in HD. Indirect pathway MSNs also display significantly smaller dendritic surface areas, due to fewer primary dendrites, which again makes them more compact and consequently more excitable [49].

There also are functional differences in synaptic inputs to direct and indirect pathway MSNs. The frequency of spontaneous excitatory postsynaptic currents (sEPSCs) is higher in indirect compared to direct pathway MSNs and large-amplitude excitatory events only occur in indirect pathway MSNs [48]. After addition of $\mathrm{GABA}_{\mathrm{A}}$ receptor blockers, which induce epileptiform activity in cortical pyramidal neurons, indirect pathway MSNs display large membrane depolarizations rarely seen in direct pathway MSNs [48]. Taken together, this evidence supports the idea that functionally indirect pathway MSNs may be more susceptible to excitatory inputs and have a greater potential to develop abnormal responses.

To study the MSNs of the direct and indirect pathways, our laboratory has begun an examination of their functional changes in two HD mouse models, the YAC128 and the BACHD. Both models display a slowly progressing phenotype over about a year of age characterized by behavioral, morphological and electrophysiological changes [51-54]. The HD mice were crossed with mice expressing EGFP under the promoter of DA D1 (direct pathway) or D2 (indirect pathway) receptors, to examine synaptic function in MSNs [55, 56]. Electrophysiological recordings were performed at different stages of phenotype progression, corresponding to the period of hyperkinesia ("early HD," 1.5 months) and the period of hypokinesia ("late HD," 12 months). As symptoms change with HD progression, it is essential to follow the course of neurotransmission throughout symptom development and age to better understand the pathophysiological changes.

We first compared intact mice and YAC128 or BACHD mice at each time point to evaluate how excitatory and inhibitory inputs were altered during the progression of the phenotype (Fig. 1A). We used a number of electrophysiological indices including analysis of spontaneous (s) and mini EPSCs and inhibitory postsynaptic currents (IPSCs), evoked EPSCs and paired-pulse stimulation to evaluate changes in synaptic inputs. Most experiments across age were conducted in the YAC128 mice and the BACHD mice were examined only at the 1.5 month time point. The outcomes for YAC128 and BACHD mice were similar and we will use examples from only the YAC128 mice in Fig. 1.

At the early stage, spontaneous excitatory and inhibitory transmission onto YAC128 direct pathway MSNs was increased, while there was no change in excitatory inputs to indirect pathway MSNs in YAC128 mice (Fig. 1A, C). The increase in excitatory transmission onto direct pathway MSNs is likely presynaptic as it persisted after blockade of action potentials with tetrodotoxin [55]. At the late stage in symptomatic YAC128 mice, excitatory synaptic transmission onto direct pathway MSNs was decreased (Fig. 1A), while inhibitory transmission was increased onto indirect pathway MSNs (Fig. 1D). Alterations in excitatory transmission are in line with our previous work demonstrating biphasic changes, increases followed by decreases, in corticostriatal glutamate synaptic activity in the YAC128 model of HD [57]. These studies provided evidence for differential and complex imbalances in glutamate and GABA transmission as the phenotype progresses. However, they are not direct indices of the change in the balance of excitatory and inhibitory inputs to the two output pathways. To examine such changes more specifically, the results have been replotted to separately compare direct and indirect pathway excitatory and inhibitory inputs in intact and the YAC128 HD mice (Fig. 1B, D).

As shown previously in young intact mice $[48,50]$, excitatory inputs are greater to MSNs of the indirect pathway than to MSNs of the direct pathway, exactly opposite to the HD mice at this age (Fig. 1B). In the 

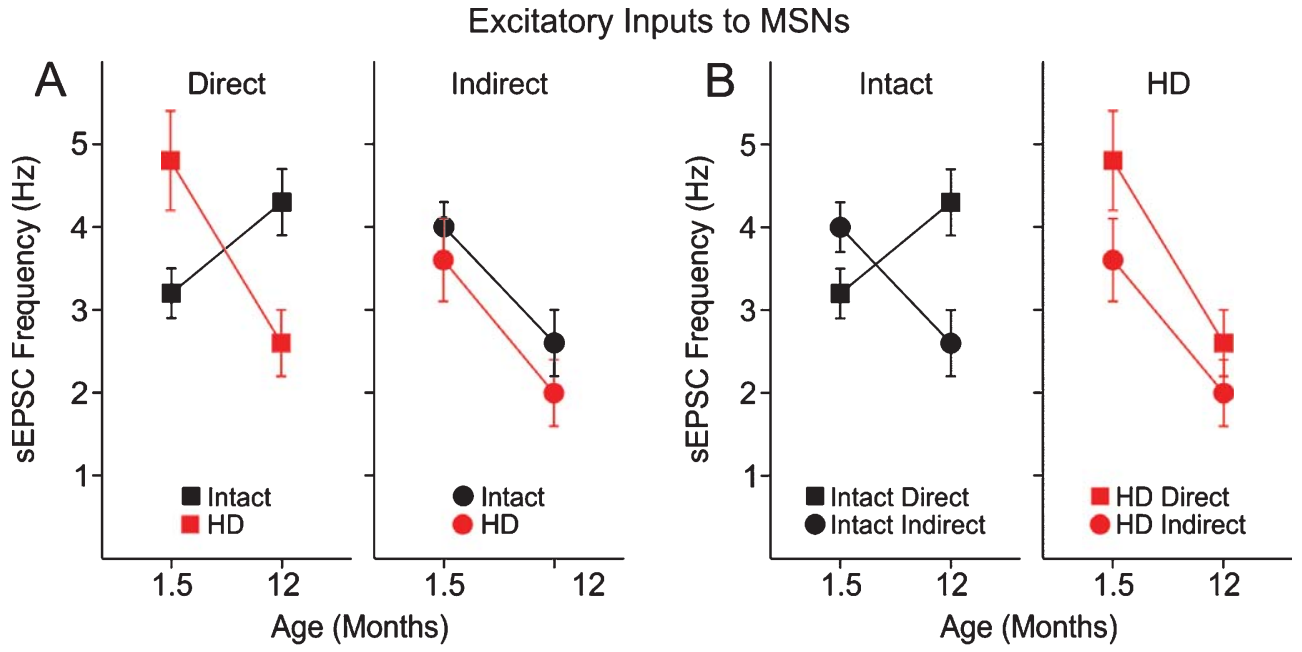

Inhibitory Inputs to MSNs
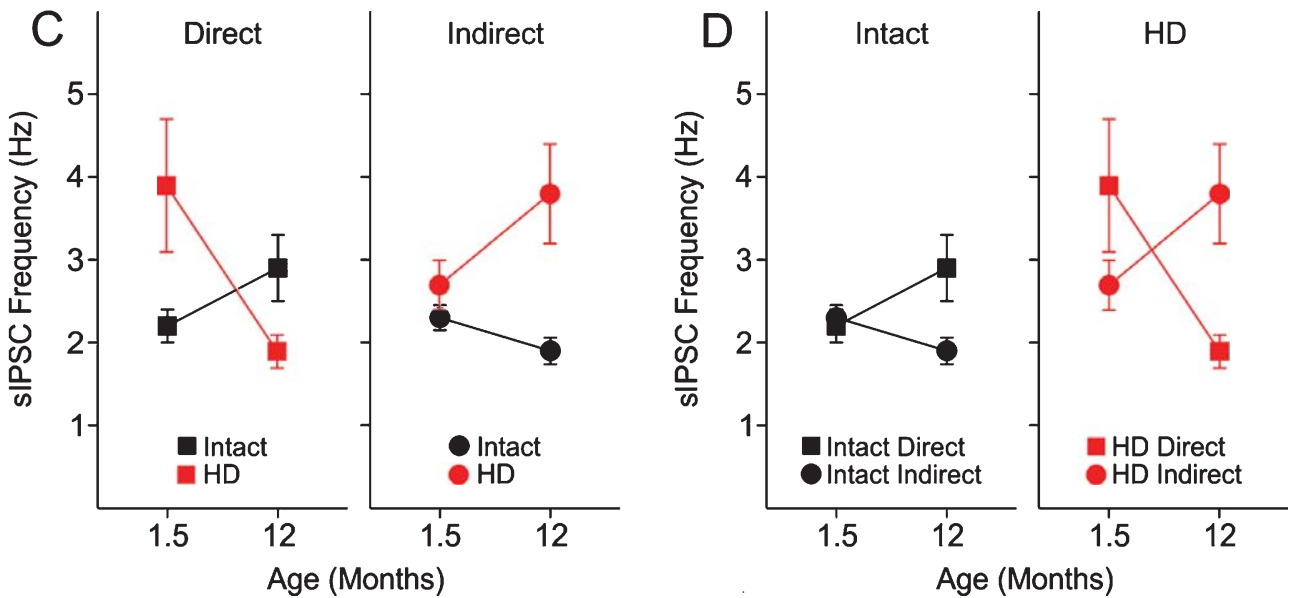

Fig. 1. Alterations in MSN excitatory and inhibitory transmission in the dorsolateral striatum of YAC128 (HD) and WT littermates (Intact). A. Graphs show comparisons of excitatory inputs (sEPSCs) to direct and indirect pathway MSNs with those of intact mice. Left graph shows that at 1.5 months, mean sEPSC frequency is higher in direct pathway HD MSNs than direct pathway MSNs from intact littermates. This difference inverts at 12 months. Right graph shows that sEPSC frequency in indirect pathway HD MSNs is similar to that of intact mice at both ages. B. Graphs show the comparisons of the balance of excitatory inputs to direct and indirect striatal output pathways for intact and HD mice at both ages. Left graph shows that the balance of excitatory inputs inverts in both pathways over age. In marked contrast, the right graph shows more excitation to direct pathway MSNs at 1.5 months and a decrease in excitation in both pathways at 12 months. C. Graphs show comparisons of inhibitory inputs (sIPSCs) to direct and indirect pathway MSNs in intact and HD mice. Left graph shows that at 1.5 months, inhibitory inputs are greater in direct pathway MSNs from HD mice than direct pathway MSNs from intact littermates. This difference inverts at 12 months. Right graph shows that inhibitory inputs to indirect pathway MSNs of HD mice is similar to that of intact mice at only 1.5 months and is increased at 12 months. D. Graphs show the comparisons of the balance of inhibitory inputs to direct and indirect striatal output pathways for intact mice and HD mice at both ages. Left graph shows that intact mice show equal inhibitory inputs at 1.5 months but increased inhibitory inputs to direct pathway MSNs at 12 months. In marked contrast inhibitory inputs to direct pathway MSNs in HD mice is increased at 1.5 months compared to indirect pathway MSNs. This pattern reverses at 12 months. Original data are replotted from [55].

intact group, inhibitory inputs to both direct and indirect pathway MSNs were similar in the young mice (Fig. 1D). Again, in contrast, there was an increase in inhibitory inputs to direct pathway MSNs compared to indirect pathway MSNs in the YAC128 mice (Fig. 1D). In the 12 month intact group, excitatory inputs to direct pathway MSNs were greater than those to indirect pathway MSNs (Fig. 1B), a reversal of the balance in the young mice. In the symptomatic 12 month YAC128 mice there was little difference in excitatory inputs to direct and indirect pathway MSNs (Fig. 1B). In the intact mice at 12 months, inhibitory input to direct 
pathway MSNs is greater than that to indirect pathway MSNs (Fig. 1D). Again, in marked contrast, in the symptomatic YAC128 mice there was an increase in inhibitory inputs to indirect pathway MSNs (Fig. 1D).

To summarize, there are significant changes in the balance of excitatory and inhibitory inputs to the direct and indirect pathway MSNs in HD compared to intact mice at each age. The alteration in this balance will have marked functional alterations in how these MSNs generate action potentials and affect the output structures, the GPi and the SNr. In intact mice at the young age the balance between the direct and indirect pathway input is to have more excitation going to indirect pathway MSNs. At one year of age, this inverts and there is more excitation going to direct pathway MSNs. The situation is markedly different in HD mice. At the early stage, the balance is inverted with more excitation going to the direct pathway MSNs. At the symptomatic stage both pathways receive about the same degree of excitatory inputs. In intact mice, inhibitory inputs differ in that at the young age they are similar to direct and indirect pathway MSNs, but at one year more inputs go to direct pathway MSNs. In symptomatic HD mice at the early stage more inhibitory inputs synapse on direct pathway MSNs and this balance inverts in symptomatic mice.

These findings underline the important role of direct pathway neurons in early HD symptoms and challenge the traditional view of a more exclusive involvement of indirect pathway neurons. Interestingly, glutamate responses evoked by cortical stimulation also are increased early in indirect pathway MSNs [55], suggesting that indeed both pathways are involved, but perhaps in different ways. However, the final outcome of differential changes is more difficult to predict as we also observed increased inhibitory inputs onto direct pathway MSNs [56], indicating the output of the direct pathway could be dampened. Additional studies in striatal output regions are needed to sort this out.

A major question arising from these findings is what is the mechanism that alters the excitatory and inhibitory inputs to direct and indirect pathway MSNs? As striatal neurotransmitter release is modulated by activation of DA receptors located on both presynaptic terminals and postsynaptically on the two types of MSNs, we hypothesized that abnormal DA transmission could underlie some of these effects. In order to begin to address this issue we examined DA modulation of synaptic inputs to direct and indirect pathway MSNs. Our laboratory has a long history of assessing the modulatory role of DA in the striatum [58, 59]. Most recently we showed that there is a DA-specific modulation of excitatory inputs to direct and indirect pathway MSNs [25]. At the postsynaptic level, low concentrations of a D1 receptor agonist consistently increased NMDA and AMPA currents in acutely isolated direct pathway MSNs while a D2 receptor agonist decreased these currents in acutely isolated indirect pathway MSNs. At the synaptic level, DA and D1 agonists increased sEPSC frequency in direct pathway MSNs whereas DA and D2 agonists decreased sEPSC frequency in indirect pathway MSNs. These effects were in part mediated through retrograde signaling via endocannabinoids. These results show that both glutamate release and postsynaptic excitatory currents are regulated in opposite directions by activation of $\mathrm{D} 1$ or D2 DA receptors and the direction of this regulation is specific to direct and indirect pathway MSNs. Thus, in our subsequent studies in HD mice we only tested D1 agonists on direct pathway MSNs and D2 agonists on indirect pathway MSNs.

We examined DA modulation in slices by testing the effect of the D1 agonist SKF81297 on sEPSC frequency in 1.5 month mice. To our surprise, while in direct pathway MSNs of intact mice, SKF81297 significantly increased sEPSC frequency it had no effect on direct pathway MSNs in YAC128 mice. In contrast, at one year of age, the D1 agonist effect was similar in direct pathway MSNs from both intact and YAC128 mice [55]. The early lack of effect of the D1 agonist on direct pathway MSNs might be induced by abnormally high DA neurotransmission at this early disease stage as we demonstrated that postsynaptic DA receptors were functional [56]. Previous studies have shown that elevated striatal DA concentrations can decrease DA receptor function [60-62]. If DA neurotransmission is elevated early in HD in the mice, then reducing it might be beneficial at this stage. It has been shown that decreasing DA concentrations with tetrabenazine (TBZ) alleviates chorea in HD patients [63]. TBZ blocks vesicular reuptake of DA and ultimately depletes stores [64]. The drug is now an FDA approved treatment for chorea. To test whether DA function could be rescued in early HD, we examined the effect of acute application of TBZ in slices. In the presence of TBZ, the D1 agonist significantly increased sEPSC frequency in direct pathway MSNs in YAC128 mice and this effect was similar to that of the D1 agonist in direct pathway MSNs in intact mice [55]. Furthermore, in direct pathway MSNs in BACHD mice, TBZ also rescued other electrophysiological changes [55]. To further examine whether alterations in glutamate and GABA transmission could be induced by abnormally elevated activation of D1 receptors, we also 
showed that SCH23390, a D1 receptor antagonist, rescued both the changes in excitatory and inhibitory synaptic transmission in direct pathway MSNs in BACHD mice [55]. Taken together, these findings suggest that at an early stage, DA tone is increased and might contribute to some of the symptoms in HD by altering neuronal activity in the direct pathway. The increase in DA tone at the early stage maximally activates D1 DA receptors on direct pathway MSNs. These findings are in line with observations that DA receptor antagonists and other agents that decrease DA reduce chorea and motor symptoms in patients and in animal models while dopaminergic stimulation can exacerbate symptoms $[65,66]$. To speculate further, the lack of effect of the D1 agonist might have been caused by decreased expression of D1 receptors at the plasma membrane as reported in other hyperdopaminergic conditions [60]. Additional studies will be required to evaluate this possibility.

We did not observe any changes in GABA or glutamate transmission in indirect pathway MSNs when a D2 receptor agonist was applied at the early stage. It remains unclear why changes in DA transmission affect glutamate and GABA synaptic activity in direct pathway MSNs while having no effects on indirect pathway MSNs, especially considering that the proportion of high-affinity D2 receptors is much greater than the proportion of high-affinity D1 receptors in the striatum [67]. As DA induces reduction of neurotransmitter release onto D2 cells via activation of pre- and postsynaptic receptors $[25,50]$, a decrease in spontaneous release could be expected in indirect pathway MSNs at the early stage. It is important to consider that DA's influence also depends on the number of receptors within a sphere of DA spillover [68]. Although no study has evaluated the number of high- and lowaffinity DA receptors, D1 receptors are in considerable excess over D2 receptors in the striatum [67, 69]. It is therefore possible that in cases of abnormal DA transmission, or DA spillover, D1 receptors will be more affected than D2 receptors. Other factors such as differential glutamate cortical and internal GABAergic striatal inputs onto direct and indirect pathway MSNs $[46,48,50,70]$ could also contribute to the prominent changes in direct pathway MSNs in early HD.

We also examined DA modulation of the direct pathway using behavioral analyses in BACHD and YAC128 mice. At the presymptomatic stage, these mice display an increase in stereotypies and TBZ rescued the stereotypy increases [55]. This evidence agrees with previous findings in patients [63] and in animal models of HD [66]. However, it remains unclear how and why the DA deficit affects the direct pathway more selectively.

\section{USING OPTOGENETICS TO EXAMINE NEURONAL SPECIFICITY IN HD}

The advent of optogenetic tools [71, 72] provides a completely novel approach to understand selective involvement of striatal neuron subtypes in normal and pathological conditions [73, 74]. Combining this tool with the use of transgenic animals expressing the EGFP reporter gene under the control of specific promoters [75] is a powerful method to answer outstanding questions in movement disorders. Optogenetic tools have already been used to show specific functional alterations of striatal output pathways in Parkinson's disease [76]. Viral-induced expression of channelrhodopsin-2 or halorhodopsin allowed activation or inhibition of MSN firing, respectively. Bradykinesia and locomotor initiation in an animal model of Parkinson's disease could be rescued by direct pathway activation with channelrhodopsin-2 [76]. In the future, behavioral analysis of direct or indirect pathway MSNs in HD mice using optical stimulation of each pathway combined with DA-regulating drugs could lead to a better understanding of these changes.

A recent study using optogenetic tools has shown that histamine is a striatal direct/indirect pathway modulator. Histamine, acting on presynaptic $\mathrm{H} 3$ receptors, decreased excitatory inputs from cortex and thalamus of direct and indirect pathway MSNs [77]. Histamine also acted on direct and indirect pathway MSNs inducing membrane depolarization and a decrease in input resistance as well as abolishing lateral inhibition between MSNs. Interestingly, studies have shown cognitive and attention deficits in HD patients who are decades before motor diagnosis [78, 79] and $\mathrm{H} 2$ and $\mathrm{H} 3$ receptors are decreased in the caudate nucleus of HD patients [80-82]. However, the functional consequence of histamine modulation in HD pathogenesis has not yet been examined but it is tempting to speculate that alterations in histamine and/or its receptors could underlie some of these changes.

\section{CONCLUSION}

Because of the great morphological and electrophysiological similarities between MSNs of the direct and indirect pathways, until recently it was difficult to tease apart their functional alterations underlying progression of the HD phenotype. The recent use of mice expressing EGFP under specific DA receptor 
promoters has permitted the examination of synaptic function in these MSNs in models of HD. The use of optogenetics will further permit dissection of the specific roles of these distinct neuronal populations in $\mathrm{HD}$, as well as other neurodegenerative disorders like Parkinson's disease [76]. In HD, the pattern of changes in direct and indirect pathway MSNs that has begun to emerge is clearly more complicated than previous morphological studies had suggested. Electrophysiological recordings reveal a critical role of direct pathway neurons in the early stage of HD. In the late stage both types of MSNs are involved. In addition, there is a strong influence of alterations in DA modulation that interact and possibly cause some of the changes in excitatory and inhibitory synaptic transmission. In the future, the use of combined optogenetics with identified neurons in each of these pathways will help unravel the next set of questions about how the output nuclei in the GP and $\mathrm{SN}$ are affected in HD.

\section{ACKNOWLEDGMENTS}

The authors would like to thank Donna Crandall for help with the illustration. Funding was provided by CHDI, Inc. and NIH Grant NS41574.

\section{DISCLOSURES}

The authors have no conflicts of interest, financial or otherwise.

\section{REFERENCES}

[1] The Huntington's Disease Collaborative Research Group. A novel gene containing a trinucleotide repeat that is expanded and unstable on Huntington's disease chromosomes. Cell. 1993;72(6):971-83.

[2] Bird ED. Chemical pathology of Huntington's disease. Annu Rev Pharmacol Toxicol. 1980;20:533-51.

[3] Bonelli RM, Hofmann P. A systematic review of the treatment studies in Huntington's disease since 1990. Expert Opin Pharmacother. 2007;8(2):141-53.

[4] Heinsen H, Rub U, Gangnus D, Jungkunz G, Bauer M, Ulmar G, et al. Nerve cell loss in the thalamic centromedianparafascicular complex in patients with Huntington's disease. Acta Neuropathol. 1996;91(2):161-68.

[5] Kassubek J, Gaus W, Landwehrmeyer GB. Evidence for more widespread cerebral pathology in early HD: an MRI-based morphometric analysis. Neurology. 2004;62(3):523-4; author reply 4.

[6] Kremer HP, Roos RA, Dingjan G, Marani E, Bots GT. Atrophy of the hypothalamic lateral tuberal nucleus in Huntington's disease. J Neuropathol Exp Neurol. 1990;49(4):371-82.

[7] Petersen A, Gil J, Maat-Schieman ML, Bjorkqvist M, Tanila $\mathrm{H}$, Araujo IM, et al. Orexin loss in Huntington's disease. Hum Mol Genet. 2005;14(1):39-47.
[8] Vonsattel JP, Myers RH, Stevens TJ, Ferrante RJ, Bird ED, Richardson EP Jr. Neuropathological classification of Huntington's disease. J Neuropathol Exp Neurol. 1985; 44(6):559-77.

[9] Vonsattel JP, DiFiglia M. Huntington disease. J Neuropathol Exp Neurol. 1998;57(5):369-84.

[10] Ferrer I, Kulisewsky J, González G, Escartín A, Chivite A, Casas R. Parvalbumin-immunoreactive neurons in the cerebral cortex and striatum in Huntington's disease. Neurodegeneration. 1994;3:169-73.

[11] Massouh M, Wallman MJ, Pourcher E, Parent A. The fate of the large striatal interneurons expressing calretinin in Huntington's disease. Neurosci Res. 2008;62(4):216-24.

[12] Rosas HD, Tuch DS, Hevelone ND, Zaleta AK, Vangel M, Hersch SM, et al. Diffusion tensor imaging in presymptomatic and early Huntington's disease: Selective white matter pathology and its relationship to clinical measures. Mov Disord. 2006;21(9):1317-25.

[13] Kita H, Kitai ST. Glutamate decarboxylase immunoreactive neurons in rat neostriatum: their morphological types and populations. Brain Res. 1988;447(2):346-52.

[14] Wilson CJ. Basal Ganglia. In: Shepherd GW, ed. The synaptic organization of the brain. Oxford: Oxford University Press, 1990;279-316.

[15] Bolam JP, Hanley JJ, Booth PA, Bevan MD. Synaptic organisation of the basal ganglia. J Anat. 2000;196(Pt 4):527-42.

[16] Smith Y, Raju DV, Pare JF, Sidibe M. The thalamostriatal system: a highly specific network of the basal ganglia circuitry. Trends Neurosci. 2004;27(9):520-7.

[17] Kemp JM. The site of termination of afferent fibres on the neurones of the caudate nucleus. J Physiol. 1970;210(1):17P$8 \mathrm{P}$.

[18] Graybiel AM. Neurotransmitters and neuromodulators in the basal ganglia. Trends Neurosci. 1990;13(7):244-54.

[19] Pisani A, Bernardi G, Ding J, Surmeier DJ. Re-emergence of striatal cholinergic interneurons in movement disorders. Trends Neurosci. 2007;30(10):545-53.

[20] Tepper JM, Wilson CJ, Koos T. Feedforward and feedback inhibition in neostriatal GABAergic spiny neurons. Brain Res Rev. 2008;58(2):272-81.

[21] Cicchetti F, Prensa L, Wu Y, Parent A. Chemical anatomy of striatal interneurons in normal individuals and in patients with Huntington's disease. Brain Res Brain Res Rev. 2000;34(12):80-101

[22] Ferrante RJ, Beal MF, Kowall NW, Richardson EP Jr., Martin JB. Sparing of acetylcholinesterase-containing striatal neurons in Huntington's disease. Brain Res. 1987;411(1):162-6.

[23] Ferrante RJ, Kowall NW, Beal MF, Richardson EP Jr., Bird ED, Martin JB. Selective sparing of a class of striatal neurons in Huntington's disease. Science. 1985;230(4725):561-3.

[24] Kawaguchi Y, Wilson CJ, Emson PC. Projection subtypes of rat neostriatal matrix cells revealed by intracellular injection of biocytin. J Neurosci. 1990;10(10):3421-38.

[25] Andre VM, Cepeda C, Cummings DM, Jocoy EL, Fisher YE, William Yang X, et al. Dopamine modulation of excitatory currents in the striatum is dictated by the expression of D1 or D2 receptors and modified by endocannabinoids. Eur J Neurosci. 2010;31(1):14-28.

[26] Shuen JA, Chen M, Gloss B, Calakos N. Drd1a-tdTomato BAC transgenic mice for simultaneous visualization of medium spiny neurons in the direct and indirect pathways of the basal ganglia. J Neurosci. 2008;28(11):2681-5.

[27] Surmeier DJ, Song WJ, Yan Z. Coordinated expression of dopamine receptors in neostriatal medium spiny neurons. J Neurosci. 1996;16(20):6579-91. 
[28] Gerfen CR, Engber TM, Mahan LC, Susel Z, Chase TN, Monsma FJ Jr., et al. D1 and D2 dopamine receptor-regulated gene expression of striatonigral and striatopallidal neurons. Science. 1990;250(4986):1429-32.

[29] Haber SN, Nauta WJ. Ramifications of the globus pallidus in the rat as indicated by patterns of immunohistochemistry. Neuroscience. 1983;9(2):245-60.

[30] Vincent S, Hokfelt T, Christensson I, Terenius L. Immunohistochemical evidence for a dynorphin immunoreactive striato-nigral pathway. Eur J Pharmacol. 1982;85(2):251-2.

[31] Albin RL, Young AB, Penney JB. The functional anatomy of basal ganglia disorders. Trends Neurosci. 1989;12(10):36675.

[32] Steiner H, Gerfen CR. Enkephalin regulates acute D2 dopamine receptor antagonist-induced immediate-early gene expression in striatal neurons. Neuroscience. 1999;88(3):795810.

[33] Albin RL, Reiner A, Anderson KD, Dure LSt, Handelin B, Balfour R, et al. Preferential loss of striato-external pallidal projection neurons in presymptomatic Huntington's disease. Ann Neurol. 1992;31(4):425-30.

[34] Menalled L, Zanjani H, MacKenzie L, Koppel A, Carpenter E, Zeitlin S, et al. Decrease in striatal enkephalin mRNA in mouse models of Huntington's disease. Exp Neurol. 2000;162(2):328-42.

[35] Reiner A, Albin RL, Anderson KD, D’Amato CJ, Penney JB, Young AB. Differential loss of striatal projection neurons in Huntington disease. Proc Natl Acad Sci U S A. 1988;85(15):5733-7.

[36] Richfield EK, Maguire-Zeiss KA, Vonkeman HE, Voorn P. Preferential loss of preproenkephalin versus preprotachykinin neurons from the striatum of Huntington's disease patients. Ann Neurol. 1995;38(6):852-61.

[37] Sapp E, Ge P, Aizawa H, Bird E, Penney J, Young AB, et al. Evidence for a preferential loss of enkephalin immunoreactivity in the external globus pallidus in low grade Huntington's disease using high resolution image analysis. Neuroscience. 1995;64(2):397-404.

[38] Deng YP, Albin RL, Penney JB, Young AB, Anderson KD, Reiner A. Differential loss of striatal projection systems in Huntington's disease: A quantitative immunohistochemical study. J Chem Neuroanat. 2004;27(3):143-64.

[39] Albin RL, Reiner A, Anderson KD, Penney JB, Young AB. Striatal and nigral neuron subpopulations in rigid Huntington's disease: Implications for the functional anatomy of chorea and rigidity-akinesia. Ann Neurol. 1990;27(4):357-65.

[40] Hedreen JC, Folstein SE. Early loss of neostriatal striosome neurons in Huntington's disease. J Neuropathol Exp Neurol. 1995;54(1):105-20.

[41] Spektor BS, Miller DW, Hollingsworth ZR, Kaneko YA, Solano SM, Johnson JM, et al. Differential D1 and D2 receptor-mediated effects on immediate early gene induction in a transgenic mouse model of Huntington's disease. Brain Res Mol Brain Res. 2002;102(1-2):118-28.

[42] Raymond LA, André VM, Cepeda C, Gladding CM, Milnerwood AJ, Levine MS. Pathophysiology of Huntington's disease: Time-dependent alterations in synaptic and receptor function. Neuroscience. 2011;198:252-73.

[43] Milnerwood AJ, Gladding CM, Pouladi MA, Kaufman AM, Hines RM, Boyd JD, et al. Early increase in extrasynaptic NMDA receptor signaling and expression contributes to phenotype onset in Huntington's disease mice. Neuron. 2010;65(2):178-90.

[44] Okamoto S, Pouladi MA, Talantova M, Yao D, Xia P, Ehrnhoefer DE, et al. Balance between synaptic versus extrasynaptic NMDA receptor activity influences inclusions and neurotoxicity of mutant huntingtin. Nat Med. 2009;15(12):1407-13.

[45] Reiner A, Jiao Y, Del Mar N, Laverghetta AV, Lei WL. Differential morphology of pyramidal tract-type and intratelencephalically projecting-type corticostriatal neurons and their intrastriatal terminals in rats. J Comp Neurol. 2003;457(4):420-40.

[46] Lei W, Jiao Y, Del Mar N, Reiner A. Evidence for differential cortical input to direct pathway versus indirect pathway striatal projection neurons in rats. $\mathrm{J}$ Neurosci. 2004;24(38):8289-99.

[47] Ballion B, Mallet N, Bezard E, Lanciego JL, Gonon F. Intratelencephalic corticostriatal neurons equally excite striatonigral and striatopallidal neurons and their discharge activity is selectively reduced in experimental parkinsonism. Eur J Neurosci. 2008;27(9):2313-21.

[48] Cepeda C, Andre VM, Yamazaki I, Wu N, Kleiman-Weiner M, Levine MS. Differential electrophysiological properties of dopamine D1 and D2 receptor-containing striatal mediumsized spiny neurons. Eur J Neurosci. 2008;27(3):671-82.

[49] Gertler TS, Chan CS, Surmeier DJ. Dichotomous anatomical properties of adult striatal medium spiny neurons. J Neurosci. 2008;28(43):10814-24.

[50] Kreitzer AC, Malenka RC. Endocannabinoid-mediated rescue of striatal LTD and motor deficits in Parkinson's disease models. Nature. 2007;445(7128):643-7.

[51] Gray M, Shirasaki DI, Cepeda C, Andre VM, Wilburn B, $\mathrm{Lu} \mathrm{XH}$, et al. Full-length human mutant huntingtin with a stable polyglutamine repeat can elicit progressive and selective neuropathogenesis in BACHD mice. J Neurosci. 2008;28(24):6182-95.

[52] Pouladi MA, Graham RK, Karasinska JM, Xie Y, Santos RD, Petersen A, et al. Prevention of depressive behaviour in the YAC128 mouse model of Huntington disease by mutation at residue 586 of huntingtin. Brain. 2009;132(Pt 4): 919-32.

[53] Slow EJ, van Raamsdonk J, Rogers D, Coleman SH, Graham RK, Deng Y, et al. Selective striatal neuronal loss in a YAC128 mouse model of Huntington disease. Hum Mol Genet. 2003;12(13):1555-67.

[54] Van Raamsdonk JM, Murphy Z, Slow EJ, Leavitt BR, Hayden MR. Selective degeneration and nuclear localization of mutant huntingtin in the YAC128 mouse model of Huntington disease. Hum Mol Genet. 2005;14(24):3823-35.

[55] Andre VM, Cepeda C, Fisher YE, Huynh M, Bardakjian N, Singh S, et al. Differential electrophysiological changes in striatal output neurons in Huntington's disease. J Neurosci. 2011;31(4):1170-82.

[56] Andre VM, Fisher YE, Levine MS. Altered balance of activity in the striatal direct and indirect pathways in mouse models of Huntington's disease. Front Syst Neurosci. 2011; 5:46.

[57] Joshi PR, Wu NP, Andre VM, Cummings DM, Cepeda C, Joyce JA, et al. Age-dependent alterations of corticostriatal activity in the YAC128 mouse model of Huntington disease. J Neurosci. 2009;29(8):2414-27.

[58] Cepeda C, Buchwald NA, Levine MS. Neuromodulatory actions of dopamine in the neostriatum are dependent upon the excitatory amino acid receptor subtypes activated. Proc Natl Acad Sci U S A. 1993;90(20):9576-80.

[59] Cepeda C, Colwell CS, Itri JN, Chandler SH, Levine MS. Dopaminergic modulation of NMDA-induced whole cell currents in neostriatal neurons in slices: contribution of calcium conductances. J Neurophysiol. 1998;79(1):82-94. 
[60] Dumartin B, Jaber M, Gonon F, Caron MG, Giros B, Bloch B. Dopamine tone regulates D1 receptor trafficking and delivery in striatal neurons in dopamine transporter-deficient mice. Proc Natl Acad Sci U S A. 2000;97(4):1879-84.

[61] Giros B, Jaber M, Jones SR, Wightman RM, Caron MG. Hyperlocomotion and indifference to cocaine and amphetamine in mice lacking the dopamine transporter. Nature. 1996;379(6566):606-12.

[62] Wu N, Cepeda C, Zhuang X, Levine MS. Altered corticostriatal neurotransmission and modulation in dopamine transporter knock-down mice. J Neurophysiol. 2007;98(1):423-32.

[63] Huntington, Study, Group. Tetrabenazine as antichorea therapy in Huntington disease: a randomized controlled trial. Neurology. 2006;66:366-72.

[64] Pettibone DJ, Pflueger AB, Totaro JA, Tetrabenazine-induced depletion of brain monoamines: mechanism by which desmethylimipramine protects cortical norepinephrine. Eur J Pharmacol. 1984;102(3-4):431-6.

[65] Mestre T, Ferreira J, Coelho MM, Rosa M, Sampaio C. Therapeutic interventions for symptomatic treatment in Huntington's disease. Cochrane Database Syst Rev. 2009;(3):CD006456.

[66] Tang TS, Chen X, Liu J, Bezprozvanny I. Dopaminergic signaling and striatal neurodegeneration in Huntington's disease. J Neurosci. 2007;27(30):7899-910.

[67] Richfield EK, Penney JB, Young AB. Anatomical and affinity state comparisons between dopamine D1 and D2 receptors in the rat central nervous system. Neuroscience. 1989;30(3):767-77.

[68] Rice ME, Cragg SJ. Dopamine spillover after quantal release: rethinking dopamine transmission in the nigrostriatal pathway. Brain Res Rev. 2008;58(2):303-13.

[69] Benn CL, Slow EJ, Farrell LA, Graham R, Deng Y, Hayden $\mathrm{MR}$, et al. Glutamate receptor abnormalities in the YAC128 transgenic mouse model of Huntington's disease. Neuroscience. 2007;147(2):354-72.

[70] Gittis AH, Nelson AB, Thwin MT, Palop JJ, Kreitzer AC. Distinct roles of GABAergic interneurons in the regulation of striatal output pathways. J Neurosci. 2010;30(6):2223-34.

[71] Boyden ES. A history of optogenetics: the development of tools for controlling brain circuits with light. F1000 Biol Rep. 2011;3:11.
[72] Yizhar O, Fenno LE, Davidson TJ, Mogri M, Deisseroth K. Optogenetics in neural systems. Neuron. 2011;71(1):9-34

[73] Gradinaru V, Mogri M, Thompson KR, Henderson JM, Deisseroth K. Optical deconstruction of parkinsonian neural circuitry. Science. 2009;324(5925):354-9.

[74] Kravitz AV, Kreitzer AC. Optogenetic manipulation of neural circuitry in vivo. Curr Opin Neurobiol. 2011;21(3):433-9.

[75] Gong S, Zheng C, Doughty ML, Losos K, Didkovsky N, Schambra UB, et al. A gene expression atlas of the central nervous system based on bacterial artificial chromosomes. Nature. 2003;425(6961):917-25.

[76] Kravitz AV, Freeze BS, Parker PR, Kay K, Thwin MT, Deisseroth K, et al. Regulation of parkinsonian motor behaviours by optogenetic control of basal ganglia circuitry. Nature. 2010;466(7306):622-6.

[77] Ellender TJ, Huerta-Ocampo I, Deisseroth K, Capogna M, Bolam JP. Differential modulation of excitatory and inhibitory striatal synaptic transmission by histamine. J Neurosci. 2011;31(43):15340-51.

[78] Lawrence AD, Hodges JR, Rosser AE, Kershaw A, ffrenchConstant C, Rubinsztein DC, et al. Evidence for specific cognitive deficits in preclinical Huntington's disease. Brain. 1998;121(Pt 7):1329-41.

[79] Paulsen JS, Langbehn DR, Stout JC, Aylward E, Ross CA, Nance M, et al. Detection of Huntington's disease decades before diagnosis: the Predict-HD study. J Neurol Neurosurg Psychiatry. 2008;79(8):874-80.

[80] Goodchild RE, Court JA, Hobson I, Piggott MA, Perry RH, Ince $\mathrm{P}$, et al. Distribution of histamine H3-receptor binding in the normal human basal ganglia: comparison with Huntington's and Parkinson's disease cases. Eur J Neurosci. 1999;11(2):449-56.

[81] Martinez-Mir MI, Pollard H, Moreau J, Traiffort E, Ruat M, Schwartz JC, et al. Loss of striatal histamine $\mathrm{H} 2$ receptors in Huntington's chorea but not in Parkinson's disease: comparison with animal models. Synapse. 1993;15(3):209-20.

[82] van Wamelen DJ, Shan L, Aziz NA, Anink JJ, Bao AM, Roos RA, et al. Functional increase of brain histaminergic signaling in Huntington's disease. Brain Pathol. 2011;21(4):419-27. 